\title{
Bicuspid aortopathy: Seeing the forest for the trees
}

\author{
Kevin L. Greason, MD
}

From the Department of Cardiovascular Surgery, Mayo Clinic, Rochester, Minn.

Disclosures: Author has nothing to disclose with regard to commercial support.

Received for publication Oct 19, 2017; accepted for publication Oct 27, 2017; available ahead of print Dec 6, 2017.

Address for reprints: Kevin L. Greason, MD, Department of Cardiovascular Surgery, Mayo Clinic, 200 First St, Southwest, Rochester, MN 55905 (E-mail: greason.kevin@mayo.edu).

J Thorac Cardiovasc Surg 2018;155:470-1

0022-5223/\$36.00

Copyright $\subset 2017$ by The American Association for Thoracic Surgery

https://doi.org/10.1016/j.jtcvs.2017.10.087

Readers of the Journal will find interest in this article on machine-learning phenotype classification of bicuspid aortopathy. ${ }^{1}$ The authors' premise is that the link between aortic morphology and valvular pathology has been incompletely characterized. This is a nicely written article that provides "seeing the forest for the trees" with respect to patterns of aortic dilatation in patients with bicuspid aortic valve. My appreciation of the article was enhanced with review of additional reading materials about machine learning and cardiovascular imaging. ${ }^{2}$

The focus of this study was to determine whether machine learning methods could discern distinct phenotype patterns of bicuspid aortopathy and then to associate the phenotype patterns with visual rules that could be recognized in computed tomography/magnetic resonance imaging (CT/MRI). The data included imaging analysis of 656 $\mathrm{CT} / \mathrm{MRI}$ scans with cross-sectional diameter measurements taken at the level of the sinuses of Valsalva, sinotubular junction, tubular ascending aorta, proximal aortic arch, and midaortic arch. Measurements were standardized for body surface area. Imaging studies were subsequently rereviewed in a blinded fashion and the visual and machine learning classifications compared.

Through a series of rather complex analyzes using unsupervised clustering algorithms, machine learning identified the bicuspid aortic valve to be associated with 3 phenotypes of aortic dilatation: (1) root (ie, aorta at the sinuses of Valsalva was larger than at the tubular ascending aorta), (2) ascending (ie, aorta at the origin of the brachiocephalic artery was smaller than at the sinotubular junction), and (3) arch (ie, aorta at the origin of the brachiocephalic artery was equal to or larger than at the sinotubular junction). Concordance with visual classification was $94 \%$.

The concept of 3 phenotypes of bicuspid aortic dilatation was previously introduced in a 2014 review article by Verma and Siu. ${ }^{3}$ Wojnarski and colleagues make the point, however, that the review article was the authors' interpretation of available literature and that no referenced study recognized all 3 phenotypes. I find the main strength of the present article to be an unbiased confirmation, based

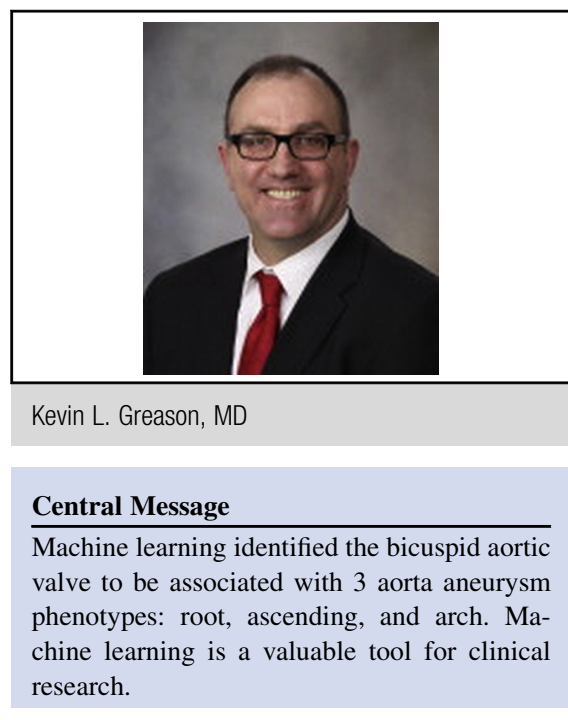

See Article page 461

on unsupervised machine learning methodology, of Verma's and Siu's patterns of bicuspid aortic dilatation. In essence, Wojnarski and colleagues provide an "it is what it is" validation of the 3 phenotypes of bicuspid aortopathy.

The main weakness of the article is a perceived selection bias. This is a retrospective analysis of patients who underwent ascending aorta surgery, and, as such, the article does not provide any data or analysis of patients who did not undergo operation. Furthermore, image analysis relied on the largest aorta cross-sectional diameter, and that may not be the best measure of size (eg, query use of area in the transcatheter aortic valve insertion experience). ${ }^{4,5}$ Finally, CT/ MRI images were assessed at a single point in time. The authors point out that identifying the true relationship between ascending aorta phenotypes will require longitudinal data.

It is my impression that the concept and analysis presented in this article affirms the potential of machine learning in clinical research. In the present analysis, machine learning confirmed human learning.

\section{References}

1. Wojnarski CM, Roselli EE, Indrees JJ, Zhu Y, Carnes TA, Lowry AM, et al. Machine-learning phenotypic classification of bicuspid aortopathy. J Thorac Cardiovasc Surg. 2018;155:461-9.

2. Henglin M, Stein G, Hushcha PV, Snoek J, Wiltschko AB, Cheng S. Machine learning approaches in cardiovascular imaging. Circ Cardiovasc Imaging. October 10, 2017 [Epub ahead of print].

3. Verma S, Siu SC. Aortic dilatation in patients with bicuspid aortic valve. $N$ Engl J Med. 2014;370:1920-9. 
4. Smith CR, Leon MB, Mack MJ, Miller DE, Moses JW, Svensson LG, et al. Transcatheter versus surgical aortic-valve replacement in high-risk patients. $N$ Engl J Med. 2011;364:2187-98.
5. Leon MB, Smith CR, Mack MJ, Makkar RR, Svensson LG, Kodali SK, et al. Transcatheter or surgical aortic-valve replacement in intermediate-risk patients N Engl J Med. 2016;374:1609-20. 